Original

Article

\title{
Chordal Reconstruction versus Leaflet Resection for Repair of Degenerative Posterior Mitral Leaflet Prolapse
}

\author{
Yeow Leng Chua, MD, ${ }^{1, *}$ Philip Y. K. Pang, MD, ${ }^{1, *}$ Yen Ping Yap, MN, ${ }^{1}$ \\ Zakir Hussain Abdul Salam, MD, MPH, ${ }^{2}$ and Yang Tian Chen, MD $^{3}$
}

\begin{abstract}
Objective: To review our experience of mitral valve repair for degenerative posterior mitral leaflet prolapse, comparing the outcomes of chordal reconstruction and leaflet resection.

Methods: From 2000 to 2014, 205 patients underwent successful repair for degenerative posterior mitral leaflet prolapse. One hundred and four $(51.5 \%)$ underwent leaflet resection (group R) and 98 (48.5\%) underwent chordal reconstruction (group C). Follow-up was $96.5 \%$ complete with a mean follow-up of $6.1 \pm 4.0$ years.

Results: Mean age was $\mathbf{5 7 . 0} \pm \mathbf{1 1 . 0}$ years. Males accounted for $\mathbf{7 3 . 8 \%}$. Ring annuloplasty was performed in $195(96.5 \%)$. There were no operative mortalities within 30 days. Overall survival was $97.8 \% \pm 1.3 \%$ at 7 years. Outcomes at 6 years: freedom from severe mitral regurgitation (group $\mathrm{R} 97.1 \% \pm \mathbf{2 . 0 \%}$, group $\mathrm{C} \mathbf{1 0 0 \%}, P=\mathbf{0 . 2 8 8}$ ), freedom from moderate or severe mitral regurgitation (group $\mathrm{R} 97.1 \% \pm 2.0 \%$, group $\mathrm{C} 94.4 \% \pm 5.4 \%, P=0.541$ ). Group $\mathrm{C}$ patients received larger annuloplasty rings and had significantly lower postoperative transmitral gradients.

Conclusions: Leaflet resection and chordal reconstruction are effective techniques for repair of degenerative posterior mitral leaflet prolapse. Both techniques result in a low incidence of recurrent mitral regurgitation. Chordal reconstruction accommodates larger annuloplasty rings and is associated with lower transmitral gradients.
\end{abstract}

Keywords: mitral valve prolapse, mitral regurgitation, mitral valve annuloplasty

${ }^{1}$ Department of Cardiothoracic Surgery, National Heart Centre Singapore, Singapore

${ }^{2}$ Alice Lee Centre for Nursing Studies, Yong Loo Lin School of Medicine, National University Singapore, Singapore

${ }^{3}$ Department of Cardiac Surgery, The First Affiliated Hospital of

Fujian Medical University, China

Received: October 29, 2015; Accepted: November 26, 2015

Corresponding author: Philip Y. K. Pang. Department of Cardiothoracic Surgery, National Heart Centre Singapore, 5 Hospital Drive, Singapore 169609

Email: philip.pang.y.k@nhcs.com.sg

*Equal contributors and co-first authors.

Presented in part as an electronic poster at the AATS Mitral Conclave 2013, New York, USA.

(C)2015 The Editorial Committee of Annals of Thoracic and Cardiovascular Surgery. All rights reserved.

\section{Introduction}

Since the pioneering work and introduction of standardized techniques for mitral valve (MV) reconstruction by Carpentier, ${ }^{1)}$ MV repair has been shown to produce excellent long-term results, and is now the established treatment of choice for patients with degenerative MV disease. ${ }^{1,2)}$

Mitral regurgitation (MR) is more common in posterior mitral leaflet (PML) prolapse compared to anterior leaflet or bileaflet prolapse. ${ }^{3)}$ Quadrangular resection of the prolapsing segment has been the most widely used surgical technique for repair of PML prolapse. ${ }^{1)}$ Although effective, leaflet resection results in immobilization of the posterior leaflet and impairs to some extent, its physiologic role. ${ }^{4)}$ 
Over the years, many different surgical techniques have been developed and surgeons are now able to successfully repair increasingly complex MV pathologies, previously deemed irrepairable. MV repair using expanded polytetrafluoroethylene (ePTFE), first introduced by David and colleagues, ${ }^{5)}$ is now widely used, with excellent long-term results recently reported.6) Cases with complex lesions which may not always be amenable to leaflet resection alone may undergo neochordal repair with good results.7)

This study aims to review the results of MV repair for isolated PML prolapse due to degenerative disease at a tertiary referral centre over a 15 year period, comparing the safety, durability and functional outcomes of chordal reconstruction and leaflet resection techniques.

\section{Materials and Methods}

Following approval from the local Centralized Institutional Review Board (reference: 2007/043/C), a retrospective case-note and database review was performed on consecutive patients who had undergone mitral valve repair for isolated posterior mitral leaflet prolapse between January 2000 and December 2014 at our tertiary referral cardiac centre.

\section{Definitions}

Early or operative mortality was defined as death within 30 days of surgery, either in hospital or after hospital discharge. Renal failure was defined as serum creatinine clearance levels lower than $60 \mathrm{ml} / \mathrm{min}$ as calculated with the Cockroft-Gault formula, or the need for renal replacement therapy.

\section{Patients}

During the period January 2000 to December 2014, 497 consecutive patients underwent MV repair at our institution, of which 205 underwent repair for isolated degenerative PML prolapse. Successful MV repair was performed in 202 patients $(98.5 \%)$ with 3 patients (1.5\%) requiring intraoperative conversion to MV replacement. Of those with successful MV repair, 104 (51.5\%) underwent leaflet resection only (group R, "resection") and the remaining 98 (48.5\%) underwent chordal reconstruction without leaflet resection (group C, "chordal reconstruction").

This study focused exclusively on patients with isolated PML prolapse caused by degenerative mitral valve disease. Patients with anterior or bileaflet prolapse and those with a history of rheumatic heart disease or endocarditis were excluded. Patients were included in the study if they underwent MV repair with either the leaflet resection technique or the chordal reconstruction technique exclusively. Those who underwent a combination of both techniques, reoperative cardiac surgery, or concomitant aortic valve replacement were excluded. Data was retrospectively collected from patient case notes and electronic records.

Patient demographics and co-morbidities are shown in Table 1. Preoperative echocardiographic data are shown in Table 2.

Male patients accounted for $73.8 \%$ of cases. Mean age at the time of operation was $57.0 \pm 11.0$ years (range 27-81). The mean age of females was significantly higher than males $(61.9 \pm 12.2$ vs $55.3 \pm 10.7$ years, $P<0.001)$. No patients had undergone previous cardiac surgery. Hyperlipidaemia was more common in patients from group $\mathrm{C}$, while other baseline parameters did not differ significantly between the 2 groups.

Using colour Doppler flow mapping, the severity of MR was classified as none/trivial (0), mild (1+), moderate (2+), moderately severe (3+) and severe (4+), in a semi-quantitative manner. The severity of MR at the time of presentation was $4+$ in 182 patients $(90.1 \%)$ and $3+$ in 20 patients $(9.9 \%)$.

The New York Heart Association (NYHA) functional class was assessed in all patients before surgery. Fifty-one (25.2\%) were in NYHA class I, 109 (54.0\%) in class II, 29 (14.4\%) in class III and $13(6.4 \%)$ in class IV.

\section{Statistical analysis}

Statistical analysis was performed with the Statistical Package for Social Science, version 17 (SPSS, Chicago, IL). Continuous variables were expressed as means with standard deviation and were compared using two-tailed t-test. Categorical variables, expressed as percentages, were analysed with chi-square or Fisher's exact test. Survival function was presented using Kaplan-Meier survival curves and comparisons performed with log-rank test. A two-tailed $P$-value less than 0.05 was used to indicate statistical significance. Adverse events were reported according to the guidelines for reporting morbidity and mortality after cardiac valvular operations. ${ }^{8)}$

\section{Operative data}

All 202 patients with successful MV repairs underwent elective surgery, which was performed via median sternotomy in 197 patients (97.5\%).The remaining 5 patients (2.5\%) underwent a robotic-assisted right mini-thoracotomy approach. Isolated MV repair was performed in 106 patients $(52.5 \%)$. In the group of 96 patients (47.5\%) with 
Table 1 Patient demographics and comorbidities

\begin{tabular}{lcccc}
\hline Variable & All patients $(\mathrm{n}=202)$ & Group R $(\mathrm{n}=104)$ & Group C $(\mathrm{n}=98)$ & $P$-value \\
\hline Male gender & $149(73.8)$ & $76(73.1)$ & $73(74.5)$ & 0.820 \\
Age (years) & $57.0 \pm 11.5$ & $57.1 \pm 12.1$ & $56.9 \pm 10.9$ & 0.913 \\
Body surface area $\left(\mathrm{m}^{2}\right)$ & $1.73 \pm 0.21$ & $1.74 \pm 0.21$ & $1.73 \pm 0.22$ & 0.614 \\
NYHA Class & $2.02 \pm 0.81$ & $2.02 \pm 0.82$ & $2.02 \pm 0.80$ & 0.992 \\
Hypertension & $92(45.5)$ & $46(44.2)$ & $46(46.9)$ & 0.699 \\
Hyperlipidaemia & $73(36.1)$ & $28(26.9)$ & $45(45.9)$ & 0.005 \\
Diabetes mellitus & $15(7.4)$ & $6(5.8)$ & $9(9.2)$ & 0.355 \\
Coronary artery disease & $32(15.8)$ & $18(17.3)$ & $14(14.3)$ & 0.557 \\
Atrial fibrillation & $49(24.3)$ & $30(28.8)$ & $19(19.4)$ & 0.117 \\
Renal failure & $3(1.5)$ & $2(1.9)$ & $1(1.0)$ & 0.596 \\
Previous stroke & $9(4.5)$ & $3(2.9)$ & $6(6.1)$ & 0.265 \\
\hline
\end{tabular}

Values for continuous variables are expressed as mean \pm standard deviation. Values for categorical variables are expressed as numbers (\%). NYHA: New York Heart Association

Table 2 Echocardiographic data

\begin{tabular}{lcccc}
\hline Preoperative & All patients $(\mathrm{n}=202)$ & Group $\mathrm{R}(\mathrm{n}=104)$ & Group C $(\mathrm{n}=98)$ & $P$-value \\
\hline MR Grade & $3.90 \pm 0.30$ & $3.93 \pm 0.25$ & $3.87 \pm 0.34$ & 0.125 \\
LAESD $(\mathrm{mm})$ & $50.1 \pm 7.2$ & $52.5 \pm 9.6$ & $48.8 \pm 9.1$ & 0.050 \\
LVESD $(\mathrm{mm})$ & $33.7 \pm 5.8$ & $34.2 \pm 5.5$ & $33.4 \pm 6.0$ & 0.488 \\
LVEDD $(\mathrm{mm})$ & $56.5 \pm 7.2$ & $57.5 \pm 7.2$ & $56.0 \pm 7.2$ & 0.301 \\
LVEF $(\%)$ & $62.8 \pm 7.9$ & $61.9 \pm 7.9$ & $63.7 \pm 7.9$ & 0.101 \\
\hline Postoperative & All patients $(\mathrm{n}=200)$ & Group R $(\mathrm{n}=104)$ & Group C $(\mathrm{n}=96)$ & $P$-value \\
\hline MR Grade & $0.54 \pm 0.74$ & $0.63 \pm 0.87$ & $0.44 \pm 0.54$ & 0.054 \\
LAESD $(\mathrm{mm})$ & $43.7 \pm 8.0$ & $45.6 \pm 9.1$ & $41.8 \pm 6.3$ & 0.001 \\
LVESD $(\mathrm{mm})$ & $31.3 \pm 7.2$ & $31.4 \pm 7.9$ & $31.1 \pm 6.4$ & 0.792 \\
LVEDD $(\mathrm{mm})$ & $47.8 \pm 6.4$ & $48.0 \pm 7.0$ & $47.5 \pm 5.9$ & 0.597 \\
MPG $(\mathrm{mmHg})$ & $3.35 \pm 1.34$ & $3.61 \pm 1.47$ & $3.06 \pm 1.15$ & 0.003 \\
LVEF $(\%)$ & $58.0 \pm 10.2$ & $58.7 \pm 10.3$ & $58.1 \pm 10.1$ & 0.945 \\
\hline
\end{tabular}

Values for continuous variables are expressed as mean \pm standard deviation. LAESD: left atrial end-systolic diameter; LVESD: left ventricular end-systolic diameter; LVEDD: left ventricular end-diastolic diameter; LVEF: left ventricular ejection fraction; MPG: mean pressure gradient; MR: mitral regurgitation

concomitant procedures, 28 patients $(13.9 \%)$ underwent coronary artery bypass grafting (CABG), $46(22.8 \%)$ underwent tricuspid valve annuloplasty and 10 (5.0\%) underwent closure of a patent foramen ovale or atrial septal defect. In patients with preoperative chronic atrial fibrillation (AF), 40 (19.8\%) underwent a concomitant modified maze procedure and 30 (14.9\%) underwent closure of the left atrial appendage.

\section{Operative technique}

All operations were performed using moderate hypothermic $\left(30-32^{\circ} \mathrm{C}\right)$ cardiopulmonary bypass (CPB). Aortic cross clamping (AXC), a combination of cold and warm blood cardioplegia for myocardial protection and flooding of the surgical field with carbon dioxide was applied in all cases. Intraoperative transesophageal echocardiography (TEE) was routinely performed in all cases. The MV was approached via a transseptal or left atrial approach, followed by segmental valve analysis.

A ring annuloplasty was performed in 195 patients (96.5\%). One hundred and thirty-eight (68.3\%) had a Colvin Galloway Futureband (Medtronic, Minneapolis, MN) implanted, 56 (27.7\%) received a Cosgrove-Edwards ring (Edwards Life-sciences, Irvine CA), 4 (2.0\%) received a Duran annuloplasty band (Medtronic) and 1 (0.5\%) received an autologous pericardial annuloplasty ring. Flexible annuloplasty rings (Cosgrove-Edwards, Duran 
and autologous pericardial) were used at our institution until Oct 2007, after which a transition of institutional practice towards the use of semi-rigid annuloplasty rings (CG Future) was adopted. Sizing of the annuloplasty ring was guided by the surface area and intercommissural distance of the anterior mitral leaflet. For patients undergoing chordal reconstruction, the ring was intentionally chosen larger than the anterior leaflet, to accommodate the posterior leaflet which would be larger compared to after leaflet resection.

Leaflet resection was performed using standard quadrangular or triangular resection techniques. Chordal reconstruction was performed using ePTFE Goretex neochordae (W.L Gore \& Associates, Flagstaff, AZ), chordal transfer, or a combination of both techniques. Artificial chordal repair involved replacement of diseased primary chords by passing a single double-armed pledgetted ePTFE suture ranging from size 3-0 to 5-0, between the papillary muscle and the free margin of the prolapsed leaflet. Multiple neochordae were used when necessary. The length of each chord was estimated based on the coaptation level of a non-prolapsing segment. MV competency was assessed by bulb syringing saline into the left ventricle, prior to final adjustments of neochordal length and tying of sutures. Chordal transfer was performed by transferring non-diseased adjacent secondary chordae to the free margin of the prolapsed leaflet. The choice of repair technique was made following systematic valve analysis. Leaflet resection was the preferred technique in patients with significantly redundant myxomatous posterior leaflet tissue. In these patients, the minimum amount of leaflet resection required to prevent post-repair systolic anterior motion was performed. Chordal reconstruction was the preferred technique used in patients with limited or no excessive posterior leaflet tissue, which was commonly observed in cases with isolated chordal rupture secondary to fibroelastic deficiency. In patients with a slight amount of excess posterior leaflet tissue amenable to either leaflet resection or chordal reconstruction, leaflet resection was routinely performed up to 2006. Beyond 2006, leaflet reconstruction was increasingly adopted to preserve posterior leaflet mobility and subsequently became the technique of choice in these patients.

All patients without contraindications to anticoagulation were discharged with a 6 week regimen of Warfarin, targeting an international normalized ratio within the range of 1.8 to 2.2. Warfarin was continued indefinitely in patients with chronic and paroxysmal AF.

\section{Results}

\section{Early outcome}

MV repair was successful in 202 patients (98.5\%) with $3(1.5 \%)$ requiring intraoperative conversion to $\mathrm{MV}$ replacement. Operative data and postoperative complications are shown in Table 3. For patients undergoing isolated $\mathrm{MV}$ repair, the duration of $\mathrm{CPB}$ and $\mathrm{AXC}$ in patients from group $\mathrm{C}$ did not differ significantly compared to patients in group $\mathrm{R}$. One patient $(0.5 \%)$ required reinstitution of CPB for correction of residual MR $(>1+)$ noted intraoperatively.

Within group C $(\mathrm{n}=98), 37$ patients $(37.8 \%)$ underwent chordal reconstruction using ePTFE neochordae only, 24 (24.4\%) utilized solely chordal transfer techniques and 37 (37.8\%) used a combination of both techniques. The mean number of artificial chords used was $1.91 \pm 0.81$. Single chords were used in 24 patients (32.4\%) and multiple chords in 50 (67.6\%). For those who underwent chordal transfer, the mean number of chords transferred was $1.93 \pm 0.87$. Single chords were transferred in 21 patients $(34.4 \%)$ and multiple chords in $40(65.6 \%)$. Compared to group R, patients from group C received larger annuloplasty rings $(30.9 \pm 2.6 \mathrm{~mm}$ vs 29.4 $\pm 2.3 \mathrm{~mm}, P<0.001$ )

There were no early mortalities or postoperative strokes within 30 days of surgery. Early postoperative AF occurred in 31 patients (15.3\%), with no significant difference between the 2 groups. Five patients $(2.5 \%)$ required insertion of a permanent pacemaker due to complete heart block or sick sinus syndrome. Three patients $(1.5 \%)$ required emergency re-exploration for postoperative bleeding. No patients developed complications of systolic anterior motion (SAM), myocardial infarction, endocarditis, thromboembolic or bleeding events within 30 days of surgery.

\section{Late outcome}

Follow-up was 96.5\% complete, with 195 patients reviewed at our institution. Data regarding follow-up was obtained by direct assessment during scheduled clinic reviews. Seven international referrals (3.5\%) were lost to follow-up. The follow-up for this study was closed on July 3, 2015 (mean follow-up period $6.1 \pm 4.0$ years).

A total of 200 patients $(99.0 \%$ ) had a follow-up echocardiographic assessment $5.3 \pm 3.6$ years after surgery. Follow-up echocardiographic data are shown in Table 2. Transmitral gradients were lower in patients from group $\mathrm{C}$, 
Table 3 Operative data and postoperative complications

\begin{tabular}{|c|c|c|c|c|}
\hline Variable & All patients $(\mathrm{n}=202)$ & Group R $(\mathrm{n}=104)$ & Group C (n=98) & $P$-value \\
\hline Isolated MV repair & $106(52.5)$ & $49(47.1)$ & $57(58.3)$ & 0.116 \\
\hline CPB time (mins) & $94.7 \pm 35.4$ & $101.1 \pm 47.2$ & $89.1 \pm 18.9$ & 0.102 \\
\hline AXC time (mins) & $63.0 \pm 21.3$ & $64.0 \pm 28.0$ & $62.0 \pm 13.3$ & 0.655 \\
\hline Combined procedures & $96(47.5)$ & $55(52.9)$ & $41(41.8)$ & 0.116 \\
\hline CABG & $28(13.9)$ & $14(13.5)$ & $14(14.3)$ & 0.865 \\
\hline Tricuspid annuloplasty & $46(22.8)$ & $24(23.1)$ & $22(22.4)$ & 0.915 \\
\hline Maze procedure & $40(19.8)$ & $25(24.0)$ & $15(15.3)$ & 0.120 \\
\hline Closure of ASD or PFO & $10(5.0)$ & $6(5.8)$ & $4(4.1)$ & 0.581 \\
\hline CPB time (mins) & $114.2 \pm 31.6$ & $113.4 \pm 34.6$ & $115.2 \pm 27.4$ & 0.407 \\
\hline AXC time (mins) & $78.9 \pm 20.8$ & $76.2 \pm 20.5$ & $82.4 \pm 20.9$ & 0.151 \\
\hline \multicolumn{5}{|l|}{ Postoperative complication } \\
\hline Re-exploration for bleeding & $3(1.5)$ & $2(1.9)$ & $1(1.0)$ & 0.596 \\
\hline Atrial fibrillation or flutter & $31(15.3)$ & $13(12.5)$ & $18(18.4)$ & 0.248 \\
\hline Acute renal failure & $3(1.5)$ & $3(2.9)$ & $0(0)$ & 0.090 \\
\hline Sternal wound infection & $5(2.5)$ & $4(3.8)$ & $1(1.0)$ & 0.196 \\
\hline Pacemaker insertion & $5(2.5)$ & $3(2.9)$ & $2(2.0)$ & 0.700 \\
\hline
\end{tabular}

Values for continuous variables are expressed as mean \pm standard deviation. Values for categorical variables are expressed as numbers (\%). ASD: atrial septal defect; AXC: aortic cross clamp; CABG: coronary artery bypass grafting; $\mathrm{CPB}$ : cardiopulmonary bypass; MV: mitral valve; PFO: patent foramen ovale

(mean pressure gradient: $3.06 \pm 1.15 \mathrm{mmHg}$ vs $3.61 \pm$ $1.47 \mathrm{mmHg}, P=0.003)$. Figure 1 shows the distribution of patients grouped according to the severity of MR on follow-up.

Overall survival was $97.8 \% \pm 1.3 \%$ at 7 years, (Group R $96.5 \% \pm 2.0 \%$ vs Group C 100\%, $P=0.156)$, (Fig. 2A). Three patients (1.5\%) from group $\mathrm{R}$ died from non-valverelated causes. There were no valve-related deaths from either group.

Freedom from reoperation at 6 years was $97.6 \% \pm$ $1.7 \%$ for group $\mathrm{R}$ and $100 \%$ for group $\mathrm{C}(P=0.264)$. Two patients $(1.0 \%)$ from group $\mathrm{R}$ required reoperation for recurrent severe MR at 2.2 years and 3.9 years respectively following MV repair. Recurrent MR was caused by multiple ruptured native chordae in one patient, requiring $\mathrm{MV}$ replacement. The other patient developed recurrent MR due to lack of leaflet coaptation at the posteromedial commissure, for which the mitral valve was successfully repaired.

Freedom from severe MR at 6 years, (Fig. 2B) was $97.1 \% \pm 2.0 \%$ for group $\mathrm{R}$ and $100 \%$ for group $\mathrm{C}(P=$ 0.288). Freedom from moderate or severe MR at 6 years, (Fig. 2C) was $97.1 \% \pm 2.0 \%$ for group $\mathrm{R}$ and $94.4 \% \pm$ $5.4 \%$ for group $\mathrm{C}(P=0.541)$.

At latest follow-up, 188 patients (93.1\%) had either none, trivial or mild MR. One hundred and eighty patients $(89.1 \%)$ were in NYHA functional class I,

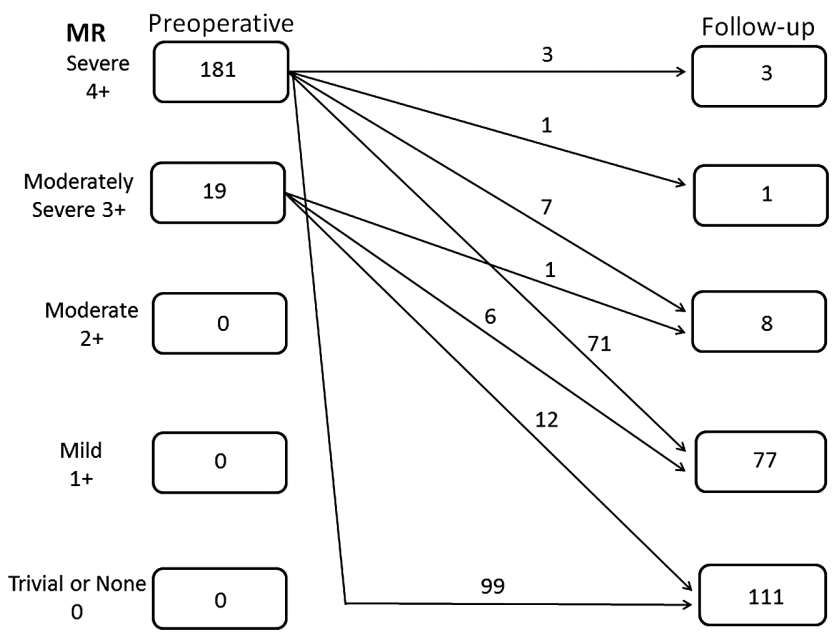

Fig. 1 Mitral regurgitation preoperatively and at latest follow-up, including the echocardiography results of two patients before reoperation. MR: mitral regurgitation

$17(8.4 \%)$ in class II, and $5(2.5 \%)$ in class III. No patients suffered thromboembolic events, myocardial infarction, endocarditis or bleeding complications. One patient $(0.5 \%)$ was treated medically for SAM which developed 5.3 years after MV repair.

\section{Discussion}

This study provides information on early and midterm clinical and echocardiographic outcomes of MV repair 

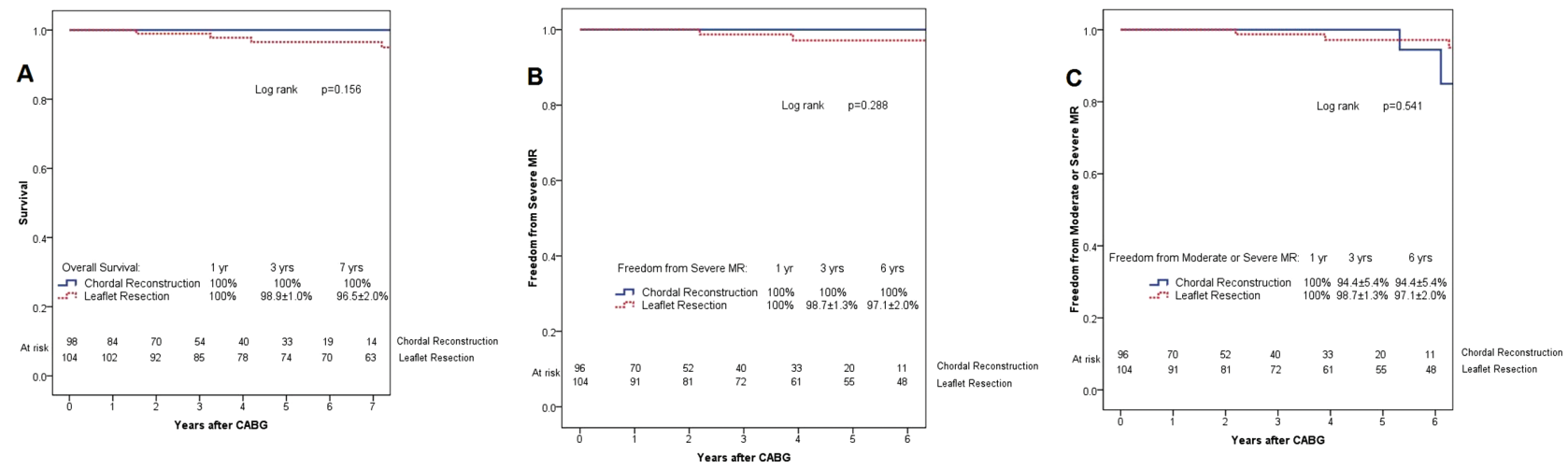

Fig. 2 Kaplan-Meier graphs. (A) Survival function for 202 patients with degenerative posterior mitral leaflet prolapse who underwent chordal reconstruction (continuous line) or leaflet resection (dotted line), (B) Freedom from severe MR for 200 patients with degenerative posterior mitral leaflet prolapse who underwent chordal reconstruction (continuous line) or leaflet resection (dotted line), (C) Freedom from moderate or severe MR for 200 patients with degenerative posterior mitral leaflet prolapse who underwent chordal reconstruction (continuous line) or leaflet resection (dotted line). MR: mitral regurgitation

for isolated PML prolapse due to degenerative disease, in a cohort of relatively young patients undergoing elective surgery.

The goals of reconstructive MV surgery are preservation or restoration of normal leaflet motion, creation of a large surface of coaptation, and stabilization of the mitral annulus with a remodeling annuloplasty. ${ }^{9)}$ The most widely used established techniques for correction of degenerative PML prolapse are quadrangular and triangular resection, in combination with a ring annuloplasty. Both techniques have been shown to produce excellent long-term results. ${ }^{1,2,10,11)}$

Leaflet resection leads to the loss of native leaflet tissue and alters the anatomic and physiologic function of the MV. This leads to an increase in leaflet stiffness resulting in restriction in leaflet mobility and reduced area of coaptation with the anterior mitral leaflet. ${ }^{4)}$ The size of the mitral annulus is reduced after repair with both leaflet resection and non-resectional techniques. Non-resectional approaches have been to shown to allow more dynamic changes in the structure of the mitral annulus during the cardiac cycle and preserve posterior leaflet mobility during the early postoperative period. ${ }^{12)}$ Preservation of the PML tissue can restore the best surface of coaptation. ${ }^{13}$

The American College of Cardiology and American Heart Association guidelines suggest targeted referral to "reference centers" to ensure that a repair rate of at least $90 \%$ is achieved, especially for patients who are asymptomatic. ${ }^{14)}$ The majority of patients in this study (79.2\%) were asymptomatic or minimally symptomatic, in
NYHA class I or II. The success rate of MV repair in this series $(98.5 \%)$ is comparable to other studies involving patients with isolated PML prolapse, with success rates ranging from $97 \%$ to $100 \%{ }^{15,16)}$ There were no operative mortalities within this series, consistent with the very low operative mortality rates ranging from $0.07 \%-2.9 \%$ associated with patients undergoing MV repair for isolated PML prolapse. ${ }^{13,15-17)}$

A prosthetic mitral annuloplasty ring was implanted in $96.5 \%$ of patients in this series. Failure to add an annuloplasty to a MV reconstructive procedure is associated with an increased risk of late reoperation. ${ }^{18,19)}$ The annuloplasty ring size for patients who underwent chordal reconstruction was significantly larger compared to those who underwent leaflet resection. Postoperative transmitral gradients were lower in the chordal reconstruction group. Left ventricular ejection fraction and left ventricular dimensions were not significantly different between the 2 groups after surgery. These findings are consistent with previous reports. ${ }^{15,17,20)}$ Further studies are required to determine the long-term clinical effects of lower transmitral gradients and larger annuloplasty rings.

Chordal reconstruction with ePTFE artificial chordae is technically demanding. Determining the appropriate length of the ePTFE suture and tying of the suture without slippage is critical for the success and durability of repair. For patients undergoing isolated MV repair in this study, there were no significant differences in the duration of CPB and AXC when comparing both repair techniques. Seeburger and colleagues ${ }^{20)}$ found that artificial chordal repair using the loop technique was associated 
with a longer duration of $\mathrm{CPB}$ and $\mathrm{AXC}$ compared to leaflet resection. There were no operative mortalities and no cardiac or valve-related mortalities during the follow up period of this study. These results compare favourably to other series with similar study populations. ${ }^{13,17,20)}$ Since valve repair does not cure the underlying degenerative process, recurrent $\mathrm{MR}$ is a potential problem in all patients who have undergone MV repair. Previous reports have described the incidence of repair failure and recurrence of severe MR being equally low with chordal replacement and quadrangular resection. ${ }^{3,13,17)}$ Results of this series were similar, whereby at 6 years, freedom from severe MR and freedom from reoperation were not significantly different between patients undergoing leaflet resection compared to those undergoing chordal reconstruction. More recent studies have reported freedom from reoperation rates favouring the non-resectional approach. ${ }^{17,20)}$ To address a main concern over the use of artificial chordae for MV repair, data supporting the longterm durability of ePTFE artificial chordae is emerging. David and colleagues ${ }^{6)}$ recently reported excellent longterm results showing freedom from re-operation and severe MR at 18 years to be $90.2 \% \pm 2.4 \%$ and $91.0 \% \pm$ $2.7 \%$ respectively.

Lesions with complex prolapse patterns involving multiple segments of the posterior leaflet and large amounts of excess leaflet tissue may not be amenable to a single technique of either leaflet resection or chordal reconstruction. Each repair must be guided by anatomical considerations specific to each patient. The most appropriate technique, or combination of resectional and non-resectional techniques if necessary, should be utilized to achieve an optimal surface of leaflet coaptation.

\section{Study limitations}

This is a retrospective observational study with inherent biases in data collection. Leaflet resection was the procedure of choice in the early years of this study and chordal reconstruction techniques were used more frequently after 2006. This limited the number of patients and duration for comparison of follow-up outcomes between groups. Further surveillance is required for evaluation of the long-term outcomes in this study population.

\section{Conclusion}

This study shows that MV repair for isolated PML prolapse using chordal reconstruction or leaflet resection techniques can be performed with excellent early and mid-term results. Both techniques are equally effective in producing good echocardiographic outcomes and can be performed with a low incidence of reoperation and mortality. Compared to leaflet resection, chordal reconstruction permits larger annuloplasty rings and is associated with lower postoperative transmitral gradients.

\section{Acknowledgements}

No commercial or other sources of funding were received for this study. The authors thank Clara Zhang and Selena Chew for their editorial assistance.

\section{Disclosure Statement}

All authors have no conflict of interest.

\section{References}

1) Carpentier A. Cardiac valve surgery-the "French correction". J Thorac Cardiovasc Surg 1983; 86: 323-37.

2) Deloche A, Jebara VA, Relland JY, et al. Valve repair with Carpentier techniques. The second decade. J Thorac Cardiovasc Surg 1990; 99: 990-1001; discussion 1001-2.

3) David TE, Omran A, Armstrong S, et al. Long-term results of mitral valve repair for myxomatous disease with and without chordal replacement with expanded polytetrafluoroethylene sutures. J Thorac Cardiovasc Surg 1998; 115: 1279-85; discussion 1285-6.

4) Dreyfus GD, Corbi P, Rubin S, et al. Posterior leaflet preservation in mitral valve prolapse: a new approach to mitral repair. J Heart Valve Dis 2006; 15: 528-30.

5) David TE, Bos J, Rakowski H. Mitral valve repair by replacement of chordae tendineae with polytetrafluoroethylene sutures. J Thorac Cardiovasc Surg 1991; 101: 495-501.

6) David TE, Armstrong S, Ivanov J. Chordal replacement with polytetrafluoroethylene sutures for mitral valve repair: a 25 -year experience. J Thorac Cardiovasc Surg 2013; 145: 1563-9.

7) Rankin JS, Orozco RE, Rodgers TL, et al. "Adjustable" artificial chordal replacement for repair of mitral valve prolapse. Ann Thorac Surg 2006; 81: 1526-8.

8) Akins CW, Miller DC, Turina MI, et al. Guidelines for reporting mortality and morbidity after cardiac valve interventions. J Thorac Cardiovasc Surg 2008; 135: 732-8.

9) Filsoufi F, Carpentier A. Principles of reconstructive surgery in degenerative mitral valve disease. Semin Thorac Cardiovasc Surg 2007; 19: 103-10.

10) Gazoni LM, Fedoruk LM, Kern JA, et al. A simplified approach to degenerative disease: triangular resections 
of the mitral valve. Ann Thorac Surg 2007; 83: 165864; discussion 1664-5.

11) Sakamoto Y, Hashimoto K, Okuyama H, et al. Longterm assessment of mitral valve reconstruction with resection of the leaflets: triangular and quadrangular resection. Ann Thorac Surg 2005; 79: 475-9.

12) Ben Zekry S, Lang RM, Sugeng L, et al. Mitral annulus dynamics early after valve repair: preliminary observations of the effect of resectional versus non-resectional approaches. J Am Soc Echocardiogr 2011; 24: 1233-42.

13) Perier P, Hohenberger W, Lakew F, et al. Toward a new paradigm for the reconstruction of posterior leaflet prolapse: midterm results of the "respect rather than resect" approach. Ann Thorac Surg 2008; 86: 718-25; discussion 718-25.

14) Nishimura RA, Otto CM, Bonow RO, et al. 2014 AHA/ACC Guideline for the Management of Patients With Valvular Heart Disease: a report of the American College of Cardiology/American Heart Association Task Force on Practice Guidelines. Circulation 2014; 129: e521-643.

15) Falk V, Seeburger J, Czesla M, et al. How does the use of polytetrafluoroethylene neochordae for posterior mitral valve prolapse (loop technique) compare with leaflet resection? A prospective randomized trial. J Thorac Cardiovasc Surg 2008; 136: 1205; discussion 1205-6.

16) Johnston DR, Gillinov AM, Blackstone EH, et al. Surgical repair of posterior mitral valve prolapse: implications for guidelines and percutaneous repair. Ann Thorac Surg 2010; 89: 1385-94.

17) Lange R, Guenther T, Noebauer C, et al. Chordal replacement versus quadrangular resection for repair of isolated posterior mitral leaflet prolapse. Ann Thorac Surg 2010; 89: 1163-70; discussion 1170.

18) Cohn LH, Couper GS, Aranki SF, et al. Long-term results of mitral valve reconstruction for regurgitation of the myxomatous mitral valve. J Thorac Cardiovasc Surg 1994; 107: 143-50; discussion 150-1.

19) Gillinov AM, Cosgrove DM, Blackstone EH, et al. Durability of mitral valve repair for degenerative disease. J Thorac Cardiovasc Surg 1998; 116: 734-43.

20) Seeburger J, Falk V, Borger MA, et al. Chordae replacement versus resection for repair of isolated posterior mitral leaflet prolapse: Ann Thorac Surg 2009; 87: 1715-20. 